\title{
Article \\ Self-Assembly of Hydrogen-Bonded Cage Tetramers of Phosphonic Acid
}

\author{
Ivan S. Giba ${ }^{1,2}$ and Peter M. Tolstoy ${ }^{1, *(D)}$ \\ 1 Institute of Chemistry, St. Petersburg State University, 198504 St. Petersburg, Russia; i.giba@spbu.ru \\ 2 Department of Physics, St. Petersburg State University, 198504 St. Petersburg, Russia \\ * Correspondence: peter.tolstoy@spbu.ru
}

\section{check for} updates

Citation: Giba, I.S.; Tolstoy, P.M. Self-Assembly of Hydrogen-Bonded Cage Tetramers of Phosphonic Acid. Symmetry 2021, 13, 258. https:// doi.org/10.3390/sym13020258

Academic Editor: Aneta Jezierska Received: 21 January 2021

Accepted: 1 February 2021

Published: 4 February 2021

Publisher's Note: MDPI stays neutral with regard to jurisdictional claims in published maps and institutional affiliations.

Copyright: (c) 2021 by the authors. Licensee MDPI, Basel, Switzerland. This article is an open access article distributed under the terms and conditions of the Creative Commons Attribution (CC BY) license (https:// creativecommons.org/licenses/by/ $4.0 /)$.

\begin{abstract}
The self-association of phosphonic acids with general formula $\mathrm{RP}(\mathrm{O})(\mathrm{OH})_{2}$ in solution state remains largely unexplored. The general understanding is that such molecules form multiple intermolecular hydrogen bonds, but the stoichiometry of self-associates and the bonding motifs are unclear. In this work, we report the results of the study of self-association of tert-butylphosphonic acid using low temperature liquid-state ${ }^{1} \mathrm{H}$ and ${ }^{31} \mathrm{P}$ NMR spectroscopy $\left(100 \mathrm{~K} ; \mathrm{CDF}_{3} / \mathrm{CDF}_{2} \mathrm{Cl}\right)$ and density functional theory (DFT) calculations. For the first time, we demonstrate conclusively that polar aprotic medium tert-butylphosphonic acid forms highly symmetric cage-like tetramers held by eight $\mathrm{OHO}$ hydrogen bonds, which makes the complex quite stable. In these associates. each phosphonic acid molecule is bonded to three other molecules by forming two hydrogen bonds as proton donor and two hydrogen bonds as proton acceptor. Though the structure of such cage-like tetramers is close to tetrahedral, the formal symmetry of the self-associate is $C_{2}$.
\end{abstract}

Keywords: hydrogen bond; low-temperature NMR; phosphonic acid; tetramer; self-association

\section{Introduction}

Self-association via multiple hydrogen bonds is characteristic for low-molecular weight compounds that exhibit both proton-donating and proton-accepting functional groups in mutual orientations that do not prevent several hydrogen bonds forming at the same time. Examples of such compounds include pyrazoles [1,2], amidines [3-5], and carboxylic acids [6-9]. Linear or cyclic self-associates, such as dimers, trimers, and tetramers, can be formed between the molecules in the gas or condensed phases [10,11]. An interesting case is presented by phosphorus-containing acids (phosphinic, phosphoric, and phosphonic), which have the $\mathrm{POH}$ and $\mathrm{P}=\mathrm{O}$ groups acting as proton donors and acceptors, respectively, thus being able to form hydrogen-bonded self-associates. Previously, we determined the stoichiometry and structure of self-associates of dimethylphosphoric [12], diphenylphosphoric, dimethylphosphinic, phenylphosphinic, and bis(2,4,4-trimethylpentyl)phosphinic acids in polar aprotic solutions using low temperature NMR $[13,14]$ and density functional theory (DFT) calculations $[15,16]$. We have shown experimentally that $\mathrm{R}_{2} \mathrm{POOH}$ and $(\mathrm{RO})_{2} \mathrm{POOH}$ acids predominantly form cyclic trimers in $\mathrm{CDF}_{3} / \mathrm{CDF}_{2} \mathrm{Cl}$ mixtures. It should be noted, however, that in the gas phase, several phosphinic and phosphoric acids most probably form cyclic dimers, as it was discussed in $[17,18]$ and supported by numerous quantum-chemical calculations [19-26]. In crystal state, phosphinic and phosphoric acids form either cyclic dimers or infinite chains, see e.g., [27-31]. Anions like $\mathrm{P}\left(\mathrm{O}^{-}\right)(\mathrm{OH})_{2}$ are able to form linear oligomers as well [32]. Besides, recently we also studied hetero-complexes formed by molecules of two different $\mathrm{POOH}$-containing acids (namely, diphenylphosphoric, dimethylphosphoric, diphenylphosphinic, and dimethylphosphinic ones), using low-temperature NMR spectroscopy and the partial hydrogen/deuterium (H/D) substitution in the mobile proton sites [33]. For such systems we showed the formation of cyclic hetero-tetramers, in addition to hetero-dimers and hetero-trimers. 
There are several papers in which the structure of self-associates of phosphonic acids, $\mathrm{RP}(\mathrm{O})(\mathrm{OH})_{2}$, are discussed. In the crystalline state, phosphonic acids form infinite ladderlike "double H-bonded" [34,35] or "triple H-bonded" chains [36], or two-dimensional sheets (see Figure 1a-c, respectively) [37]. Judging from these structural motifs, one could conclude that the presence of two $\mathrm{OH}$ groups, their relative orientation in the $\mathrm{P}(\mathrm{O})(\mathrm{OH})_{2}$ moiety, as well as the strong tendency of the $\mathrm{P}=\mathrm{O}$ group to form two hydrogen bonds place phosphonic acids as versatile and underexplored synthons for the design of $\mathrm{H}$ bonded molecular crystals [38,39]. In disordered environments, the structure of phosphonic acid self-associates are less known. For example, phenylphosphonic acid encapsulated in mesoporous silica (SBA-15 and aminopropyl-modified SBA-15) forms an amorphous state between liquid and solid with unknown structure, as the crystallinity is broken by the confinement [40]. The ability of phosphonic acids to form extended hydrogenbonded networks has several industrial applications. For example, in proton conducting polymer membranes, phosphonic acid moieties presumably form H-bonded chains of various lengths and structures, which serve as a path for the long-range proton transfer (Grotthuss mechanism) [41-43]. Phosphonic acid-based organic and organic-inorganic coatings are used as alternative surface treatments for aluminum [44] and titanium [45,46]. Self-assembled monolayers (SAMs) of phosphonic acid-based molecules are commonly used to modify the surface of dielectrics [47-49].

a)

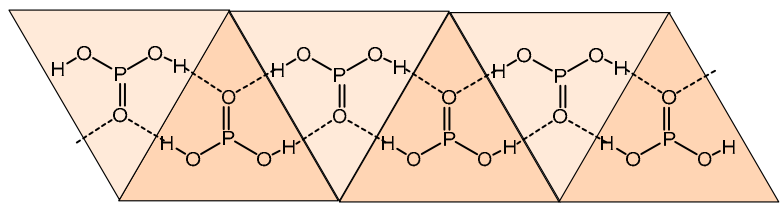

c)

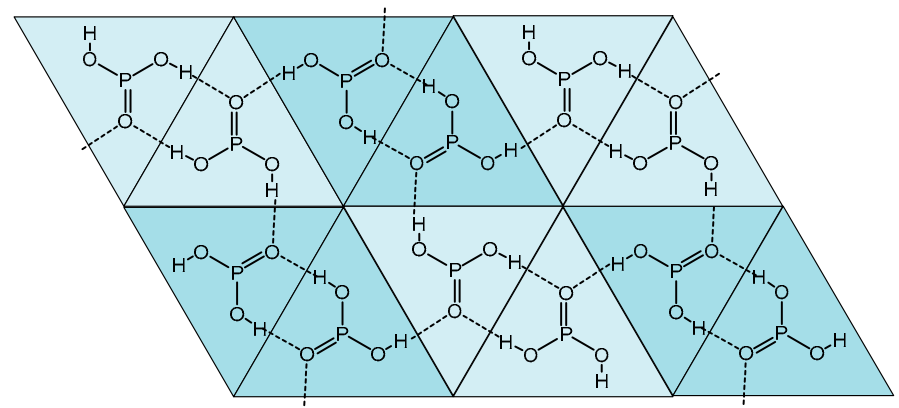

b)

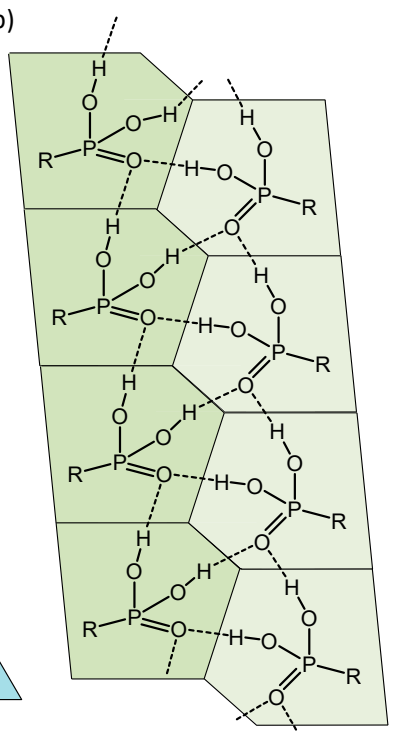

Figure 1. The hydrogen bond motifs in crystalline forms of phosphonic acids: (a) infinite ladder-like "double H-bonded" chains, (b) "triple H-bonded" chains, and (c) two-dimensional sheets.

In this work, we report the results of the study of self-association of tert-butylphosphonic acid (see Figure 2) using low temperature liquid-state ${ }^{1} \mathrm{H}$ and ${ }^{31} \mathrm{P}$ NMR spectroscopy and DFT calculations. For the first time, we demonstrate conclusively that polar aprotic medium tert-butylphosphonic acid forms cage-like tetramers held by eight $\mathrm{OHO}$ hydrogen bonds. 

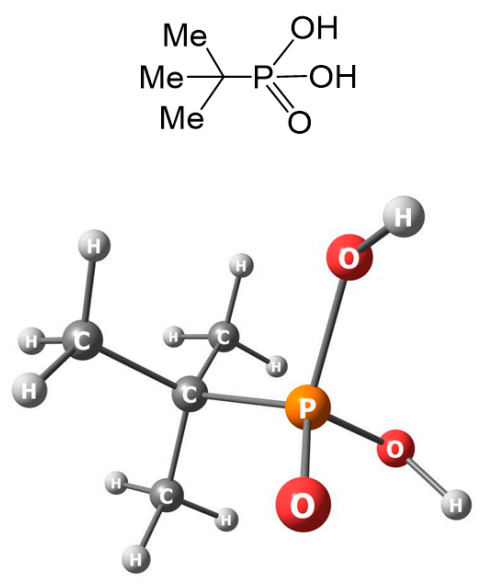

Figure 2. Structure of tert-butylphosphonic acid: (top) schematic, (bottom) calculated for the gas phase (B3LYP/6-311++G(d,p)).

\section{Experimental}

For sample preparation, tert-Butylphosphonic acid was purchased from Sigma-Aldrich and used without further purification. Tert-Butylphosphonic acid was weighed and placed into a thick-walled NMR tube with a J. Young valve (Wilmad low pressure/vacuum NMR tube 522-LPV-7). Finally, to all the samples, a mixture of liquefied freonic gases $\left(\mathrm{CDF}_{3} / \mathrm{CDF}_{2} \mathrm{Cl}\right)$ was added as a solvent by vacuum transfer. This mixture was synthesized by a modified method of Siegel and Anet [50]. The overall concentration of the samples was in the range $0.001-0.025 \mathrm{M}$.

For NMR measurements, low-temperature (down to $110 \mathrm{~K}$ ) liquid-state NMR spectra were recorded at the Center for Magnetic Resonance (St. Petersburg State University Research Park) on a Bruker Avance III $500 \mathrm{MHz}$ NMR spectrometer (11.74 T, $500.03 \mathrm{MHz}$ for ${ }^{1} \mathrm{H}$ and $202.42 \mathrm{MHz}$ for ${ }^{31} \mathrm{P}$ ). The $1 \mathrm{D}$ sequence with power-gated decoupling scheme was used for the measurements of ${ }^{31} \mathrm{P}\left\{{ }^{1} \mathrm{H}\right\}$ NMR spectra. $30^{\circ}$-pulses were used with an acquisition time of $2.6 \mathrm{~s}$ for ${ }^{1} \mathrm{H}$ and $0.8 \mathrm{~s}$ for ${ }^{31} \mathrm{P}$, and the relaxation delay was $6.5 \mathrm{~s}$ for both nuclei. Spectra were recorded as the sum of 128 and 256 scans for ${ }^{1} \mathrm{H} /{ }^{1} \mathrm{H}\left\{{ }^{31} \mathrm{P}\right\}$ and ${ }^{31} \mathrm{P} /{ }^{31} \mathrm{P}\left\{{ }^{1} \mathrm{H}\right\}$ spectra, respectively. ${ }^{1} \mathrm{H}$ and ${ }^{31} \mathrm{P}$ NMR chemical shifts were calibrated using the deuterium signal of $\mathrm{CDClF}_{2}(7.17 \mathrm{ppm})$ as an internal standard and recalculated to the conventional tetramethylsilane (TMS) and $\mathrm{H}_{3} \mathrm{PO}_{4}\left(85 \%\right.$ in $\left.\mathrm{H}_{2} \mathrm{O}\right)$ scales using the unified $\Xi$ scale, according to IUPAC recommendations [51].

QC calculations were carried out at the Computing Center (St. Petersburg State University Research Park) using the Gaussian 16 package [52]. The optimized geometries and vibrational frequencies were obtained by means of density functional theory (DFT) at the B3LYP /6-311++G(d,p) level under vacuum conditions. This level of theory was chosen for its accessibility and reasonably good performance for the description of hydrogen-bonded systems [53] at a low computational cost. The isotropic ${ }^{1} \mathrm{H}$ and ${ }^{31} \mathrm{P}$ NMR chemical shieldings were obtained using the gauge-independent atomic orbitals GIAO method at the same level of theory, as were spin-spin coupling constants. The calculated ${ }^{1} \mathrm{H}$ NMR shieldings were converted into chemical shifts in tetramethylsilane (TMS) scale: $\delta_{\mathrm{H}}=\sigma_{\mathrm{H}}(\mathrm{TMS})-\sigma_{\mathrm{H}}$. The calculated ${ }^{31} \mathrm{P}$ NMR shieldings were converted to chemical shifts by using the monomeric $\mathrm{H}_{3} \mathrm{PO}_{4}$ molecule in vacuum as a standard: $\delta_{\mathrm{P}}=\sigma_{\mathrm{P}}\left(\mathrm{H}_{3} \mathrm{PO}_{4}\right)-\sigma_{\mathrm{P}}$. This approach has inherent imperfections, as outlined in [54], but it seems to be one of the most common approaches used in the literature and it serves the purpose of this work sufficiently well [15]. The visualization of obtained structures was carried out using GaussView 5.0 [55] and Chemcraft. [56] The simulation of the NMR spectra was done using the gNMR software [57]. Analysis of the electron density maps within the framework of Bader's Quantum Theory of Atoms in Molecules (QTAIM) and characterization of bond critical points $(\mathrm{BCPs})$ of the $(3,-1)$ type for $\mathrm{OHO}$ bonds was done using AIM2000 2.0 software [58,59]. 


\section{Results and Discussion}

Figure 3 shows the low-temperature $(180-110 \mathrm{~K}){ }^{1} \mathrm{H},{ }^{1} \mathrm{H}\left\{{ }^{31} \mathrm{P}\right\},{ }^{31} \mathrm{P}$, and ${ }^{31} \mathrm{P}\left\{{ }^{1} \mathrm{H}\right\} \mathrm{NMR}$ spectra of a sample containing tert-butylphosphonic acid dissolved in a $\mathrm{CDF}_{3} / \mathrm{CDF}_{2} \mathrm{Cl}$ mixture. For visual clarity, the signals are centered at $0 \mathrm{ppm}$ to compensate for the temperature dependence of chemical shifts (ca. $0.014 \mathrm{ppm}$ per $10 \mathrm{~K}$ in ${ }^{1} \mathrm{H}$ NMR spectra and ca. $0.07 \mathrm{ppm}$ per $10 \mathrm{~K}$ in ${ }^{31} \mathrm{P}$ spectra; the non-centered signals are shown in Figure $\mathrm{S} 1$ in Supplementary Information). This temperature dependence reflects a slight shortening of hydrogen bonds upon decrease of temperature; in turn, the hydrogen bond shortening is caused by an increase of the dielectric constant of the solvent, which is typical for freonic gases and their mixtures [60].
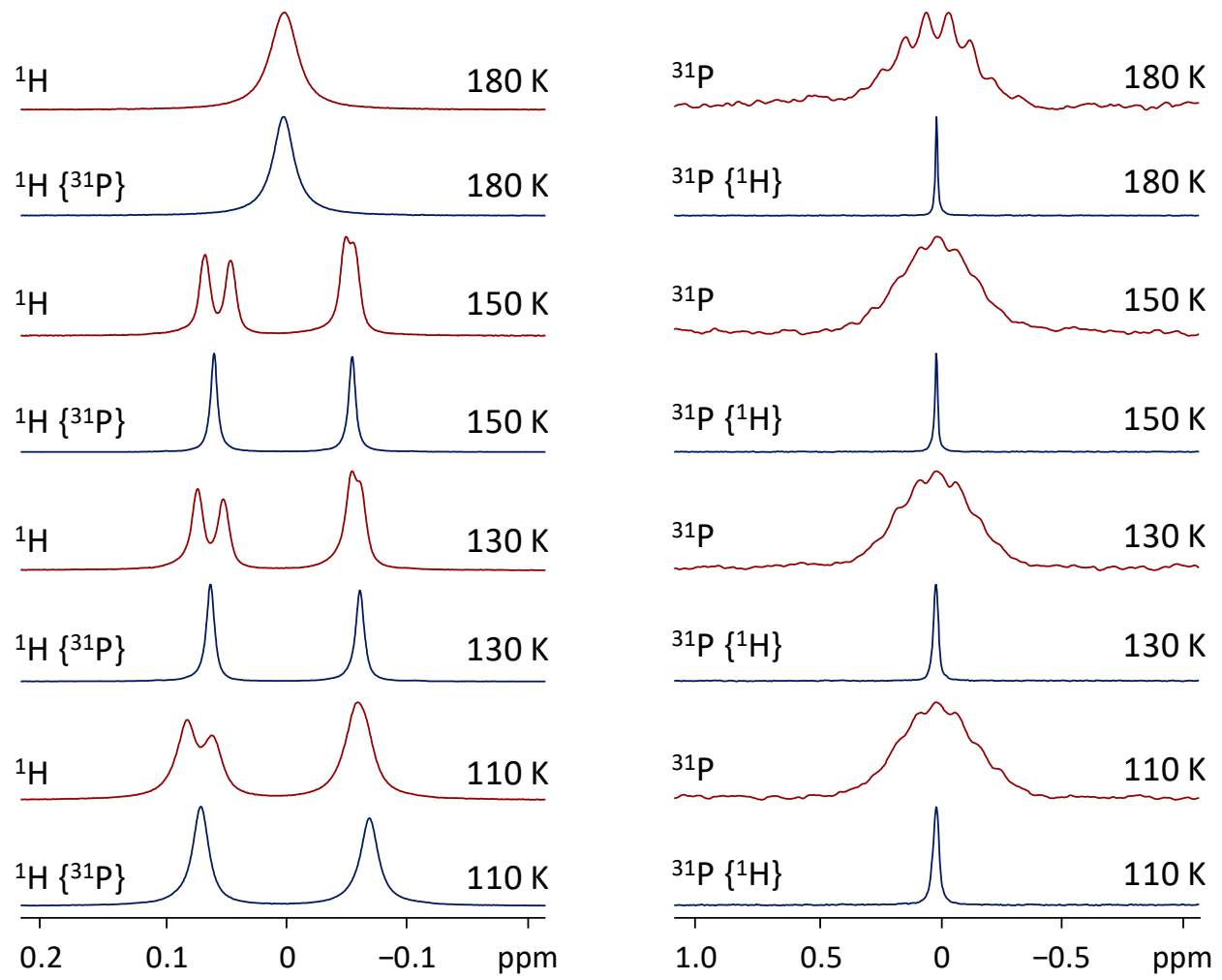

Figure 3. Temperature dependences of low-field parts of ${ }^{1} \mathrm{H}$ and ${ }^{1} \mathrm{H}\left\{{ }^{31} \mathrm{P}\right\}$ NMR spectra (left) and ${ }^{31} \mathrm{P}$ and ${ }^{31} \mathrm{P}\left\{{ }^{1} \mathrm{H}\right\} \mathrm{NMR}$ spectra (right) of tert-Butylphosphonic acid in a mixture of $\mathrm{CDF}_{3} / \mathrm{CDF}_{2} \mathrm{Cl}$.

At temperatures below $180 \mathrm{~K}$, two signals are resolved in the proton spectra, which coincide exactly in intensity, from which it can be concluded that the solution contains only one type of self-associates, which exhibits nonequivalent hydrogen bonds that have different chemical shifts of the bridging protons and, thus, different strengths of hydrogen bonds [61-63]. All phosphorus nuclei in these self-associates are equivalent, as evidenced by the single ${ }^{31} \mathrm{P}$ NMR signal. At $130 \mathrm{~K}$, the absolute values of chemical shifts are approximately 11.9 and $11.8 \mathrm{ppm}$ for ${ }^{1} \mathrm{H}$ and $43.8 \mathrm{ppm}$ for ${ }^{31} \mathrm{P}$, as shown below in Figure 4 . The value of the chemical shifts of $\mathrm{OH}$ protons indicates the formation of strong (or mediumstrong) $\mathrm{OHO}$ hydrogen bonds, while the observation of separate $\mathrm{OH}$ signals indicates that the chemical exchange between nonequivalent bridging protons is slow in the NMR time scale. 

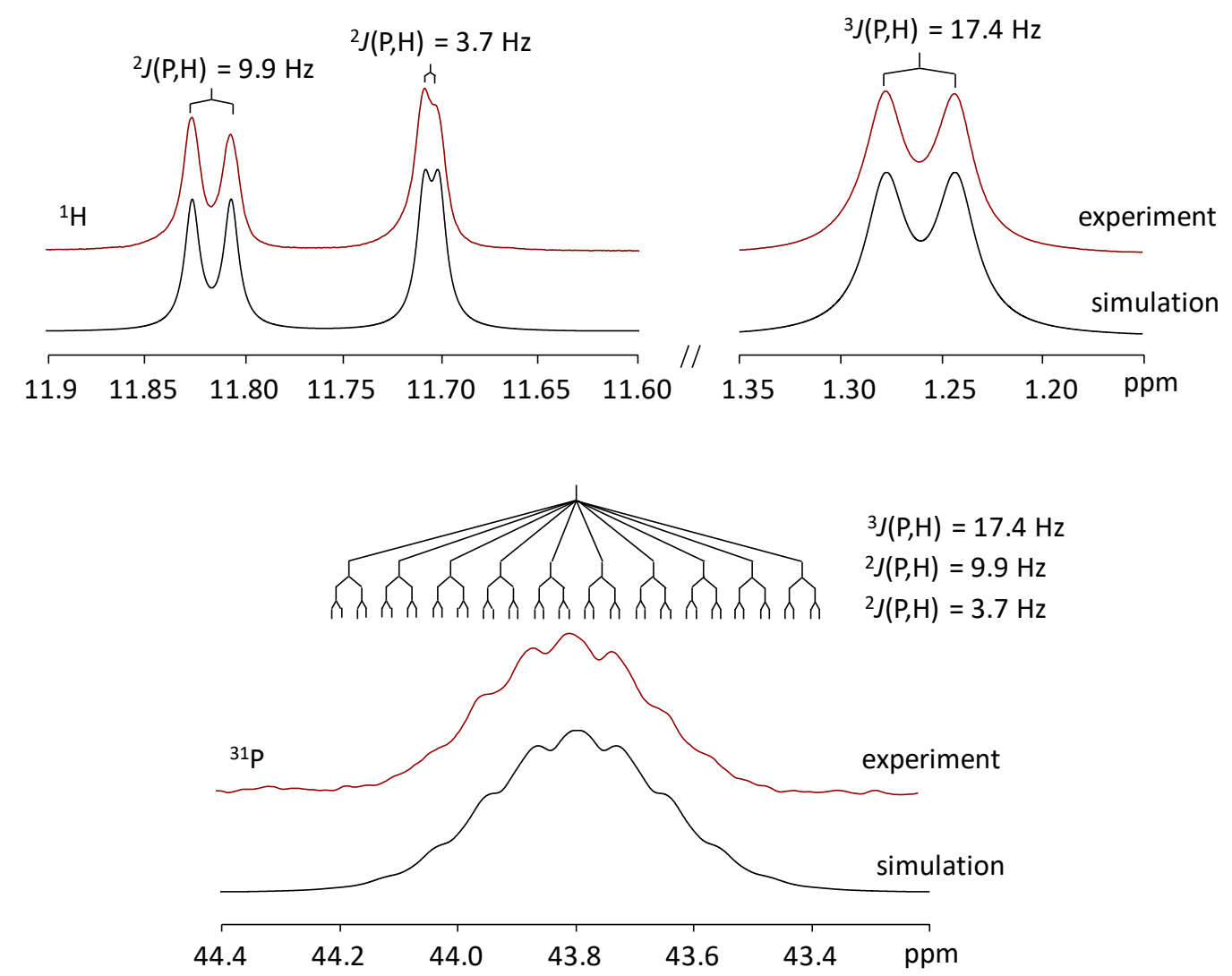

Figure 4. Fragments of ${ }^{1} \mathrm{H}$ (top) and ${ }^{31} \mathrm{P}$ (bottom) $\mathrm{NMR}$ spectra of tert-butylphosphonic acid dissolved in $\mathrm{CDF}_{3} / \mathrm{CDF}_{2} \mathrm{Cl}$ at $130 \mathrm{~K}$. Below the experimental spectra, the simulation of the multiplet structure is shown. The values of the spin-spin coupling constants are given above the signals.

The proton signals are split into doublets with $9.9 \mathrm{~Hz}$ and $3.7 \mathrm{~Hz}$ couplings. Since there was no splitting in the phosphorus-decoupled ${ }^{1} \mathrm{H}$ NMR spectra $\left({ }^{1} \mathrm{H}{ }^{31} \mathrm{P}\right\}$ spectra), we conclude that both couplings correspond to the spin-spin interaction ${ }^{2} \mathrm{~J}(\mathrm{P}, \mathrm{H})$ either directly in the $\mathrm{POH}$ group or across the hydrogen bond in the $\mathrm{PO} \cdots \mathrm{HO}$ fragment; in the last case, the constants can also be significant (several Hz) [64]. The question which of these two possibilities are correct will be discussed below, while here, looking ahead, we will assume that the observed coupling corresponds to the interaction within the $\mathrm{POH}$ group. In protondecoupled phosphorus spectra $\left({ }^{31} \mathrm{P}\left\{{ }^{1} \mathrm{H}\right\}\right.$ spectra), there is one narrow signal which, when the decoupling is turned off, transformed into a multiplet. Line shape analysis of multiplets performed using the gNMR 5.0 software (Adept Scientific) is shown in Figure 4. It could be seen that the ${ }^{31} \mathrm{P}$ NMR signal was split due to the two abovementioned ${ }^{2} J(\mathrm{P}, \mathrm{H})$ couplings as well as an additional spin-spin interaction, ${ }^{3} J(\mathrm{P}, \mathrm{H})=17.4 \mathrm{~Hz}$, with nine chemically equivalent $\mathrm{CH}$ protons of the tert-butyl group, whose signal is shown in the top right corner of Figure 4.

Thus, considering the obtained solution-state spectral data in its entirety, we can conclude that acid molecules which form self-associates are chemically equivalent, and each one of them forms two hydrogen bonds as a proton donor and, accordingly, two hydrogen bonds as a proton acceptor. In turn, these four hydrogen bonds are divided into two groups, which differ by the proton chemical shift value. Keeping in mind the symmetry of tert-butylphosphonic acid molecule, it seems impossible to propose the structure of a cyclic dimer or a cyclic trimer that would explain all of the features of the obtained spectra (for example, in cyclic dimers and trimers, either all $\mathrm{OH}$ groups are equivalent, or free $\mathrm{OH}$ groups remain that are not involved in the formation of strong hydrogen bonds; this is confirmed by the results of quantum chemical calculations, see below). The search for the simplest structure that satisfies all the spectral requirements led us to conclude that that 
the molecules of tert-butylphosphonic acid self-assemble into three-dimensional tetramers, which have a cage-like structure. Such tetramer formation can be regarded as the result of interaction of two cyclic dimers, where "free" $\mathrm{OH}$ groups form hydrogen bonds with the remaining unoccupied lone pairs of oxygen atoms of the $\mathrm{P}=\mathrm{O}$ groups of another dimer (see Figure 5a). As a result, a nonplanar structure is stabilized, in which not only all eight $\mathrm{OH}$ protons are involved in hydrogen bonds, but also each $\mathrm{P}=\mathrm{O}$ group is involved in two hydrogen bonds as a proton acceptor. In other words, neither free $\mathrm{OH}$ groups nor free electron pairs of the $\mathrm{P}=\mathrm{O}$ group remain in this structure, which makes it more stable and complicates the rearrangement of hydrogen bonds, which could lead to various proton exchange processes [8]. The protons highlighted in different colors in Figure 5a remain chemically nonequivalent.

a)

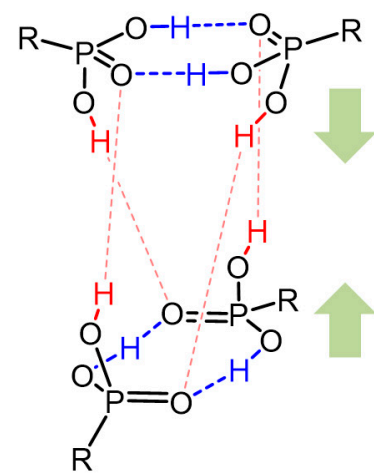

b)

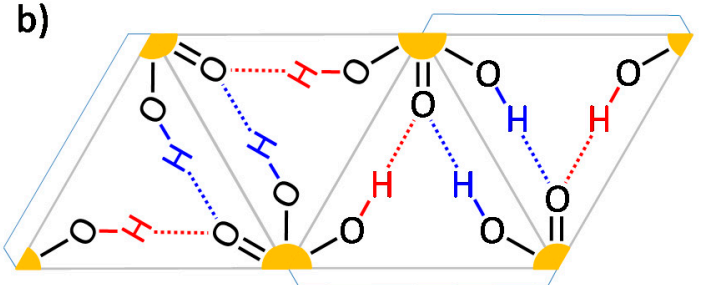

d)

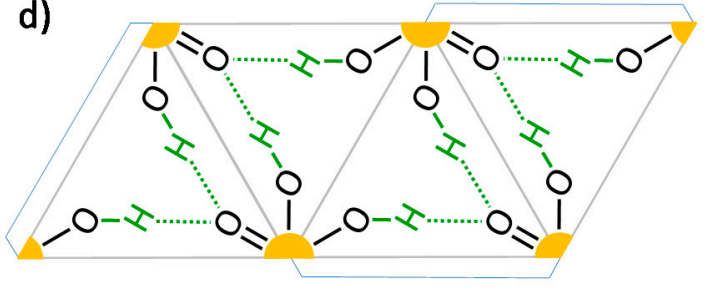

c)

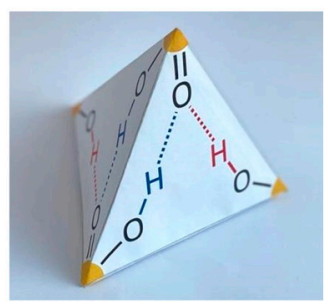

e)

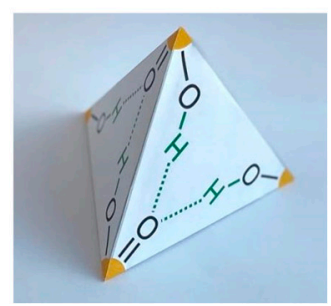

Figure 5. (a) The self-assembly of phosphonic acid tetramer: two cyclic dimers approach each other and form four additional hydrogen bonds; $\left.\mathrm{R}=-\mathrm{C}\left(\mathrm{CH}_{3}\right)_{3}\right)$. (b,c) Unfolded and assembled tetrahedron models showing the layout of hydrogen bonds in phosphonic acid tetramer. (d,e) Unfolded and assembled models of a tetrahedron depicting an alternative arrangement of hydrogen bonds in a phosphonic acid tetramer, which does not correspond to the experimental spectra. Orange dots at the vertices of the tetrahedra represent phosphorus atoms.

The structure of the tetramer could be visualized as an unfolded tetrahedron (see Figure $5 b$ ), at the vertices of which there are phosphorus nuclei, and on each face, two hydrogen bonds of $\mathrm{OHO}$ are depicted, bridging protons which are color-coded, demonstrating their chemical nonequivalence. A papercut pattern and assembled tetrahedron is shown in Figure $5 \mathrm{c}$. It should be noted that there is another way to construct a non-planar tetramer from four phosphonic acid molecules. The unfolded and assembled models of this tetramer are shown in Figure 5d,e. The larger versions of the papercut patterns can be found in the Supplementary Information, Figure S2. In the alternative layout (Figure 5e), however, the symmetry of the self-associate is higher and the protons in all eight hydro- 
gen bonds are chemically equivalent, which does not correspond to the experimental ${ }^{1} \mathrm{H}$ NMR spectrum, so this option is not considered further. One version of the tetrahedron (Figure 5c) can be converted into another one (Figure 5e) as a result of a double proton transfer in one of the "dimeric" fragments. However, under experimental conditions at temperatures below $180 \mathrm{~K}$, this does not happen; otherwise, two signals of bridging protons in the ${ }^{1} \mathrm{H}$ NMR spectrum would average out.

Additional and quite convincing evidence for the formation of a tetramer was given by the results of quantum-chemical calculations (DFT at the B3LYP/6-311++G(d,p) level). The optimized tetramer structure is shown in Figure 6a. The calculated values of chemical shifts and spin-spin coupling constants are shown in Figure $6 \mathrm{~b}$.

a)
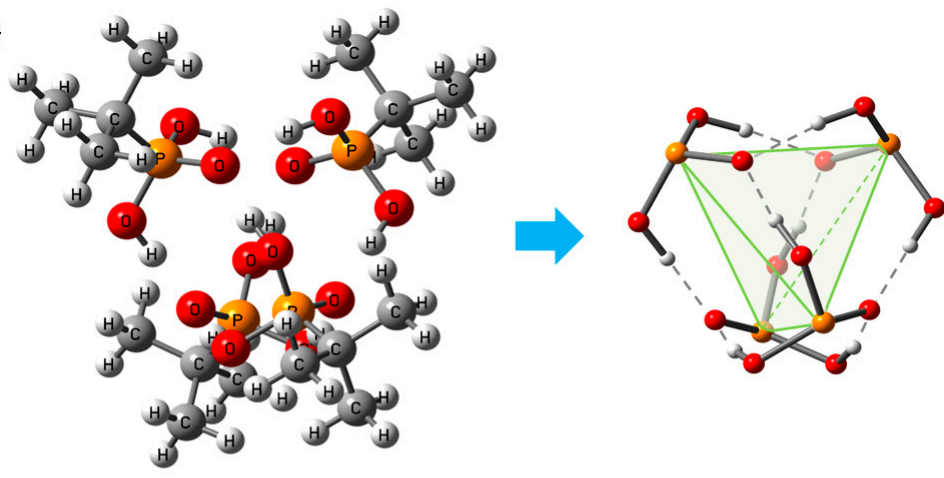

b)

experiment

calculation
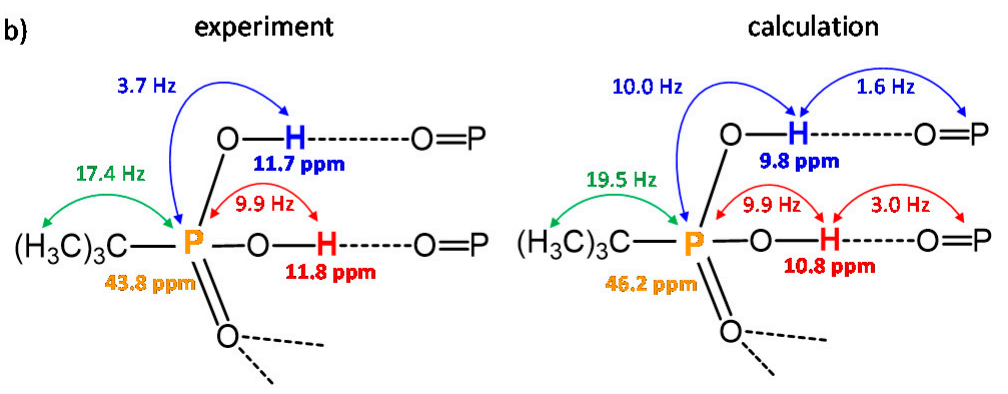

Figure 6. (a) Optimized (B3LYP/6-311++G(d,p)) structure of tetramer of tert-butylphosphonic acid in vacuum: (left) the complete structure, and (right) the same structure in which the tert-butyl groups have been omitted for clarity. (b) The values of chemical shifts and coupling constants calculated for the tetramer of tert-butylphosphonic acid.

Indeed, in such tetramers, all four ${ }^{31} \mathrm{P}$ nuclei are chemically equivalent, and the eight bridging protons are divided into two groups of four, which differ by the chemical shift value. The formal symmetry of the tetramer is $C_{2}$ (this is evident upon inspection of the Figure 5a), but the distances between all four phosphorus atoms are rather similar (the P ... P distance is ca. $4.2 \AA$ within the "dimer" and ca. $4.6 \AA$ between the "dimers"), so that the overall structure of the tetramer looks similar to a slightly distorted tetrahedron, as visualized in Figure 6a, right. The calculated values of chemical shifts agree relatively well with experiment. The chemical shift of ${ }^{31} \mathrm{P}$ is higher than the experimental one by $2.5 \mathrm{ppm}$, and the chemical shifts of the bridging protons are less than the experimental ones by about $2 \mathrm{ppm}$. The hydrogen bonds connecting two "dimeric" fragments of the tetramer turned out to be shorter, and the bridging protons in them are less shielded than in the hydrogen bonds within the "dimers" themselves. The agreement of the calculated spin-spin coupling constants with the experiment is worse. However, it can be seen that the value of the $\underline{\mathrm{POH}}$ coupling is much larger than the value of the $\underline{\mathrm{PO}} \cdots \underline{\mathrm{HO}}$ coupling (10 $\mathrm{Hz}$ and 1-3 Hz, respectively). Based on this, we assumed that the experimentally observed signal splittings in ${ }^{1} \mathrm{H}$ NMR spectra are due to the $\underline{\mathrm{PO}} \underline{\mathrm{H}}$ coupling. Nevertheless, caution should be exercised here, since the calculated values of the spin-spin coupling constants are very sensitive, both to the geometry of the hydrogen bonds and to the 
level of theory at which the calculation was performed. Additionally, we performed quantum-chemical calculations of self-associates with a different stoichiometry (using the examples of phosphonic, methylphosphonic, phenylphosphonic, and tert-butylphosphonic acids). However, in the case of cyclic dimers and trimers, the optimized structures did not correspond to the experimental spectra. Each molecule had one $\mathrm{OH}$ group participated in the formation of a ring of hydrogen bonds, and the second remained free (see the case of tert-butylphosphonic acid presented in Figures S3 and S4 in Supplementary Information).

The formation of hydrogen-bonded tetramers is a rather rare type of association since, as a rule, it is not favorable in terms of entropy. The entropy loss can be small if the molecules retain high conformational mobility relative to each other within the complex [15], or the entropy loss could be compensated by the high complexation enthalpy. Previously, hydrogen-bound cyclic (ring) tetramers were found in crystals [1,65-67] or in solution [33,68], and tetramers were also considered experimentally (IR) [69] and theoretically [70] for methanol, but in the latter case, the structure with tetrahedral symmetry (with the equivalence of all four molecules) was obtained only dynamically, as a result of successive proton transfers and rearrangements of hydrogen bonds in the cluster. As far as we know, experimental proof of the existence of stable hydrogen-bonded "tetrahedral" tetramers in an aprotic medium is presented here for the first time. It can be assumed that such tetrameric structures are fully or partially retained in the disordered medium of proton-conducting polymers synthesized on the basis of phosphonic acids.

The reasons for the high stability of tert-butylphosphinic acid tetramers are not entirely clear. At a first glance, the tetramer lacks high conformational mobility of acid molecules relative to each other, which could reduce the entropy loss. It is also difficult to suggest the presence of a fast (in the NMR timescale) dynamic process associated with proton transitions and switching of hydrogen bonds in a tetramer. Such a process would lead to a different spectral picture, namely, to the averaging of two bridging proton signals or to the changes of their multiplicities into triplets due to spin-spin interaction with two phosphorus nuclei on either side of the hydrogen bridge. However, it is difficult to completely exclude any motion within the tetramer based on the available data. Finally, it could be noted that structures of sufficiently high symmetry and without charge separation, such as the tetramer described above, do not have additional stabilization factors in a polar medium (dielectric constant of a freonic mixture $>30$ at $110 \mathrm{~K}$ ) [60]. Summarizing all these arguments, we attribute the high stability of the tetramer primarily to the enthalpy contribution due to the formation of eight strong hydrogen bonds. Indeed, quantum chemical calculations of the enthalpy, entropy, and Gibbs free energy of formation of cyclic dimers, cyclic trimer, and "tetrahedral" tetramers of tert-butylphosphonic acid in the gas phase (see Table S1 and the accompanying text) support this conclusion. The high strength of hydrogen bonds in self-associates of phosphorus-containing acids was previously noted in several publications [16,71]. Estimates of the hydrogen bond strengths in the optimized tetramer structure based on the theory of R. Bader (Atoms in Molecules, AIM) [72,73] give average values of about $14 \mathrm{kcal} / \mathrm{mol}$ per bond (depending on whether the $E_{\mathrm{V}}$ or $E_{\mathrm{G}}$ value at bond critical point was used to estimate the bond strength) or ca. $110 \mathrm{kcal} / \mathrm{mol} \mathrm{per}$ tetramer (the total average values of $E_{\mathrm{V}}=-94.4 \mathrm{kcal} / \mathrm{mol}$ and $E_{\mathrm{G}}=-127.2 \mathrm{kcal} / \mathrm{mol}$ ); see Figure S5 in Supplementary Information. These values of hydrogen bond strengths are consistent with what one could expect from the changes of ${ }^{1} \mathrm{H}$ NMR chemical shifts upon complexation (in our case, tetramerization brings about ca. $8 \mathrm{ppm}$ low-field shift of the $\mathrm{OH}$ proton signal), for which a very rough conversion factor " $1-2 \mathrm{kcal} / \mathrm{mol}$ per 1 ppm shift" could be used (it varies for different types of H-bonds and various subsets of complexes) [74-76]. Previously, based on quantum-chemical calculations, the hydrogen bond energies in cyclic self-associates of phosphinic and phosphoric acids were estimated to be within the range 10-14 $\mathrm{kcal} / \mathrm{mol}$ [16], which matches reasonably well with what we see here for tert-butylphosphonic acid. Such hydrogen bonds could be classified as medium-strong or strong ones, depending on one's frame of reference [10]. 


\section{Conclusions}

In this work, we tackled the largely unexplored question of the self-association of phosphonic acids $\mathrm{RP}(\mathrm{O})(\mathrm{OH})_{2}$ in polar aprotic media, using the example of tert-butylphosphonic acid dissolved in $\mathrm{CDF}_{3} / \mathrm{CDF}_{2} \mathrm{Cl}$ mixture. Judging from the spectral patterns observed in the low temperature ${ }^{1} \mathrm{H}$ and ${ }^{31} \mathrm{P}$ NMR spectra, we conclude that only one type of self-associate is formed under such conditions. The following could be stated about this complex: (a) all acid molecules are equivalent; (b) all $\mathrm{OH}$ protons form strong hydrogen bonds (besides, half of $\mathrm{OH}$ protons are chemically non-equivalent to the other half); (c) both types of $\mathrm{OH}$ protons exhibit spin-spin coupling to a single ${ }^{31} \mathrm{P}$ nucleus; and (d) below $150 \mathrm{~K}$, there is no fast chemical exchange between non-equivalent $\mathrm{OH}$ protons. Assuming the lowest stoichiometry of the self-associate, we conclude that it is a cage-like tetramer shaped as a distorted tetrahedron, which matches quite well with the results of quantum-chemical modelling. The formation of such tetramers could be envisioned as the result of interaction between "free" $\mathrm{OH}$ groups and $\mathrm{P}=\mathrm{O}$ groups of two cyclic dimers approaching each other. In the emerging tetramer, each acid molecule is bonded to three other molecules by strong hydrogen bonds (eight bonds in total), thus making such complexes quite enthalpically stable.

Supplementary Materials: The following are available online at https://www.mdpi.com/2073-8 994/13/2/258/s1. Figure S1: Temperature dependencies of low-field parts of ${ }^{1} \mathrm{H},{ }^{1} \mathrm{H}^{31}{ }^{31} \mathrm{P},{ }^{31} \mathrm{P}$ and ${ }^{31} \mathrm{P}\left\{{ }^{1} \mathrm{H}\right\}$ NMR spectra of tert-butylphosphonic acid in $\mathrm{CDF}_{3} / \mathrm{CDF}_{2} \mathrm{Cl}$, Figure S2: Papercut patterns for the assembly of the tetrahedron models showing the layout of hydrogen bonds in phosphonic acid tetramer, Figure S3: Two projections of the equilibrium structures of tert-butylphosphonic acid cyclic dimer and trimer, Figure S4: The comparison of calculated ${ }^{1} \mathrm{H}$ NMR spectra of cyclic dimer, cyclic trimer and cage-like tetramer of tert-butylphosphonic acid with its experimental low-temperature ${ }^{1} \mathrm{H}$ NMR spectrum, Figure S5: The QTAIM topological analysis of the electron density at the OHO hydrogen bond critical points (BCP) of tert-butylphosphonic acid, Table S1: The thermodynamic parameters of the dimerization, trimerization and tetramerization reaction of tert-butylphosphonic acid.

Author Contributions: Conceptualization, P.M.T.; methodology, I.S.G. and P.M.T.; investigation, I.S.G.; writing, I.S.G. and P.M.T.; supervision, P.M.T.; funding acquisition, P.M.T. All authors have read and agreed to the published version of the manuscript.

Funding: This work has received financial support from the Russian Foundation for Basic Research (RFBR), grant No. 19-33-90047.

Institutional Review Board Statement: Not applicable.

Informed Consent Statement: Not applicable.

Data Availability Statement: The data presented in this study are available on request from the corresponding author.

Acknowledgments: We thank Mikhail Vovk (Center for Magnetic Resonance; St. Petersburg State University Research Park) for his help in conducting the NMR experiments. The authors are grateful to Maria Polyakova for structure modelling.

Conflicts of Interest: The authors declare no conflict of interest.

\section{References}

1. Klein, O.; Aguilar-Parrilla, F.; Lopez, J.; Jagerovic, N.; Elguero, J.; Limbach, H.-H. Dynamic NMR Study of the Mechanisms of Double, Triple, and Quadruple Proton and Deuteron Transfer in Cyclic Hydrogen Bonded Solids of Pyrazole Derivatives. J. Am. Chem. Soc. 2004, 126, 11718-11732. [CrossRef]

2. Castaneda, J.P.; Denisov, G.S.; Kucherov, S.Y.; Schreiber, V.M.; Shurukhina, A.V. Infrared and Ab Initio Studies of Hydrogen Bonding and Proton Transfer in the Complexes Formed by Pyrazoles. J. Mol. Struct. 2003, 660, 25-40. [CrossRef]

3. Limbach, H.-H.; Seiffert, W. Dynamic Processes in Systems with Hydrogen Bonds. I. 1H-NMR Spectroscopic Study of the Cis-Trans Equilibrium and the Hydrogen Bond Association of $\mathrm{N}, \mathrm{N}^{\prime}$-bis(pentadeuterophenyl)-1-amino-3-iminopropene in Carbon Disulfide. Ber. Bunsen Ges. Phys. Chem. 1974, 78, 532-537. 
4. Limbach, H.-H.; Seiffert, W. Dynamic Processes in Systems with Hydrogen Bonds. II. 1H-NMR Spectroscopic Study of the Direct and Indirect Intermolecular Proton Exchange of N, $\mathrm{N}^{\prime}$-bis(pentadeuterophenyl)-1-amino-3-iminopropene in Carbon Disulfide. Ber. Bunsen Ges. Phys. Chem. 1974, 78, 641-647.

5. Lopez, J.; Maennle, F.; Wawer, I.; Buntkowsky, G.; Limbach, H.-H. NMR Studies of Double Proton Transfer in Hydrogen Bonded Cyclic N,N'-Bis-arylformamidine Dimers: Conformational Control, Kinetic HH/HD/DD Isotope Effects and Tunneling. Phys. Chem. Chem. Phys. 2007, 9, 4498-4513. [CrossRef]

6. Torres, V.; Lopez, J.-M.; Langer, U.; Buntkowsky, G.; Vieth, H.-M.; Elguero, J.; Limbach, H.-H. Kinetics of Coupled Double Proton and Deuteron Transfer in Hydrogen-Bonded Ribbons of Crystalline Pyrazole-4-carboxylic Acid. Z. Phys. Chem. 2012, 226, 1125-1147. [CrossRef]

7. Xue, Q.; Horsewill, A.; Johnson, M.; Trommsdorff, H. Tunneling Dynamics of Double Proton Transfer in Formic Acid and Benzoic Acid Dimers. J. Chem. Phys. 2004, 120, 11107-11119. [CrossRef]

8. Tolstoy, P.M.; Schah-Mohammedi, P.; Smirnov, S.N.; Golubev, N.S.; Denisov, G.S.; Limbach, H.-H. Characterization of Fluxional Hydrogen-Bonded Complexes of Acetic Acid and Acetate by NMR: Geometries and Isotope and Solvent Effects. J. Am. Chem. Soc. 2004, 126, 5621-5634. [CrossRef]

9. Tolstoy, P.M.; Smirnov, S.N.; Shenderovich, I.G.; Golubev, N.S.; Denisov, G.S.; Limbach, H.-H. NMR Studies of Solid State-Solvent and H/D Isotope Effects on Hydrogen Bond Geometries of 1:1 Complexes of Collidine with Carboxylic Acids. J. Mol. Struct. 2004, 700, 19-27. [CrossRef]

10. Gilli, G.; Gilli, P. The Nature of the Hydrogen Bond. Outline of a Comprehensive Hydrogen Bond Theory; Oxford University Press: Oxford, UK, 2009; p. 251.

11. Asfin, R.E.; Denisov, G.S.; Mielke, Z.; Tokhadze, K.G. Particular Features of the $v(\mathrm{OH})$ Absorption Band of Strongly HydrogenBonded Complexes in the Gas Phase, Low-Temperature Matrices, and Crystalline Films at 12-600 K. Opt. Spectrosc. 2005, 99, 56-67. [CrossRef]

12. Detering, C.; Tolstoy, P.M.; Golubev, N.S.; Denisov, G.S.; Limbach, H.-H. Vicinal H/D Isotope Effects in NMR Spectra of Complexes with Coupled Hydrogen Bonds. Phosphoric Acids. Doklady Phys. Chem. 2001, 379, 1-4. [CrossRef]

13. Giba, I.S.; Mulloyarova, V.V.; Denisov, G.S.; Tolstoy, P.M. Influence of Hydrogen Bonds in 1:1 Complexes of Phosphinic Acids with Substituted Pyridines on ${ }^{1} \mathrm{H}$ and ${ }^{31}$ P NMR Chemical Shifts. J. Phys. Chem. A 2019, 123, 2252-2260. [CrossRef] [PubMed]

14. Mulloyarova, V.V.; Giba, I.S.; Kostin, M.A.; Denisov, G.S.; Shenderovich, I.G.; Tolstoy, P.M. Cyclic Trimers of Phosphinic Acids in Polar Aprotic Solvent: Symmetry, Chirality and H/D Isotope Effects on NMR Chemical Shifts. Phys. Chem. Chem. Phys. 2018, 20, 4901-4910. [CrossRef] [PubMed]

15. Giba, I.S.; Mulloyarova, V.V.; Denisov, G.S.; Tolstoy, P.M. Sensitivity of ${ }^{31}$ P NMR Chemical Shifts to Hydrogen Bond Geometry and Molecular Conformation for Complexes of Phosphinic Acids with Pyridines. Magn. Reson. Chem. 2021. [CrossRef] [PubMed]

16. Mulloyarova, V.V.; Giba, I.S.; Denisov, G.S.; Tolstoy, P.M. Conformational Mobility and Proton Transfer in Hydrogen-bonded Dimers and Trimers of Phosphinic and Phosphoric acids. J. Phys. Chem A 2019, 123, 6761-6771. [CrossRef] [PubMed]

17. Asfin, R.E.; Denisov, G.S.; Tokhadze, K.G. The Infrared Spectra and Enthalpies of Strongly Bound Dimers of Phosphinic Acids in the Gas Phase. $\left(\mathrm{CH}_{2} \mathrm{Cl}\right)_{2} \mathrm{POOH}$ and $\left(\mathrm{C}_{6} \mathrm{H}_{5}\right)_{2} \mathrm{POOH}$. J. Mol. Struct. 2002, 608, 161-168. [CrossRef]

18. Asfin, R.E.; Denisov, G.S.; Poplevchenkov, D.N.; Tokhadze, K.G.; Velikanova, T.V. IR v(OH) Band and Dimerization of Phosphorous Acids in the Gas Phase and Solid State. Pol. J. Chem. 2002, 76, 1223-1231.

19. Mó, O.; Yáñez, M.; Gonzalez, L.; Elguero, J. Spontaneous Self-ionization in the Gas Phase: A Theoretical Prediction. Chem. Phys. Chem. 2001, 2, 465-467. [CrossRef]

20. Ahmadi, I.; Rahemi, H.; Tayyari, S.F. Structural, Potential Surface and Vibrational Spectroscopy Studies of Hypophosphorous Acid in the Gas Phase and Chain Conformation. A Theoretical Study. J. Korean Chem. Soc. 2005, 49, 129-137. [CrossRef]

21. Gonzalez, L.; Mó, O.; Yáñez, M.; Elguero, J. Very Strong Hydrogen Bonds in Neutral Molecules: The phosphinic acid dimers. J. Chem. Phys. 1998, 109, 2685-2693. [CrossRef]

22. Picazo, O.; Alkorta, I.; Elguero, J.; Mó, O.; Yáñez, M. Chiral Recognition in Phosphinic Acid Dimers. J. Phys. Org. Chem. 2005, 18, 491-497. [CrossRef]

23. Rekik, N.; Ghalla, H.; Hanna, G. Explaining the Structure of the OH Stretching Band in the IR Spectra of Strongly Hydrogenbonded Dimers of Phosphinic Acid and Their Deuterated Analogs in the Gas Phase: A Computational Study. J. Phys. Chem. A 2012, 116, 4495-4509. [CrossRef]

24. Yue, B.; Yan, L.; Han, S.; Xie, L. Proton Transport Pathways in an Acid-Base Complex Consisting of a Phosphonic Acid Group and a 1,2,3-Triazolyl Group. J. Phys. Chem. B 2013, 117, 7941-7949. [CrossRef] [PubMed]

25. Fedorova, I.V.; Krishtal, S.P.; Kiselev, M.G.; Safonova, L.P. Structure of Orthophosphoric Acid-N,N-dimethylformamide Complexes. Russian J. Phys. Chem. 2006, 80, 7-13. [CrossRef]

26. Yoo, T.; Nguyen, H.D.; Nilsson, M. Molecular Dynamics Investigations of Di-Butyl-Phosphoric Acid-Parameterization and Dimerization. J. Phys. Chem. B 2018, 122, 12040-12048. [CrossRef] [PubMed]

27. Solka, J.L.; Reis, A.H., Jr.; Mason, G.W.; Lewey, S.M.; Peppard, D.F. Sterically Hindered Solvent Extractants-III: The Molecular and Crystal Structure and Heavy-Element Extraction Properties of the Di-t-pentylphosphinic Acid Dimer. J. Inorg. Nucl. Chem. 1978, 40, 663-668. [CrossRef]

28. Fenske, D.; Mattes, R.; Lons, J.; Tebbe, K.F. Die Kristallstruktur von Diphenylphosphinsaure. Chem. Ber. 1973, 106, 1139-1144. (In German) [CrossRef] 
29. Reis, A.H., Jr.; Peterson, S.W.; Druyan, M.E.; Gebert, E.; Mason, G.W.; Peppard, D.F. Sterically Hindered Solvent Extractants. 2. A Neutron-Diffraction Study of the Di-tertbutylphosphinic Acid Dimer Showing Strong Asymmetric Hydrogen Bonding. Inorg. Chem. 1976, 15, 2748-2752. [CrossRef]

30. Druyan, M.E.; Reis, A.H., Jr.; Gebert, E.; Peterson, S.W.; Mason, G.W.; Peppard, D.F. Dimeric Structure of di-tert-butylphosphinic Acid. J. Amer. Chem. Soc. 1976, 98, 4801-4805. [CrossRef]

31. Bruckmann, J.; Kruger, C.; Lehmann, C.W.; Leitner, W.; Rust, J.; Six, C. Ethylenebis(phosphonic acid). Acta Cryst. C 1999, 55, 695-696. [CrossRef]

32. Fatila, E.M.; Pink, M.; Twum, E.B.; Karty, J.A.; Flood, A.H. Phosphate-Phosphate Oligomerization Drives Higher Order Coassemblies with Stacks of Cyanostar Macrocycles. Chem Sci. 2018, 9, 2863-2872. [CrossRef]

33. Mulloyarova, V.V.; Ustimchuk, D.O.; Filarowski, A.; Tolstoy, P.M. H/D Isotope Effects on ${ }^{1}$ H NMR Chemical Shifts in Cyclic Heterodimers and Heterotrimers of Phosphinic and Phosphoric Acids. Molecules 2020, 25, 1907. [CrossRef]

34. Merz, K.; Knüfer, A. Cyclohexylphosphonic Acid. Acta Cryst. 2002, C58, o187-o188. [CrossRef] [PubMed]

35. Belabassi, Y.; Gushwa, A.F.; Richards, A.F.; Montchamp, J.-L. Structural Analogues of Bioactive Phosphonic Acids: First Crystal Structure Characterization of Phosphonothioic and Boranophosphonic Acids. Elem. Phosphorus Sulfur Silicon Relat. Elem. 2008, 183, 2214-2228. [CrossRef]

36. Aragoni, M.C.; Arca, M.; Blake, A.J.; Lippolis, V.; Schroder, M.; Wilson, C. 4-Methoxyphenylphosphonic Acid: Reactivity of Lawesson's Reagent. Acta Cryst. 2002, C58, o260-o262. [CrossRef] [PubMed]

37. Mahmoudkhania, A.H.; Langer, V. Phenylphosphonic Acid as a Building Block for Two-Dimensional Hydrogen-Bonded Supramolecular Arrays. J. Mol. Struct. 2002, 609, 97-108. [CrossRef]

38. Desiraju, G.R. Supramolecular Synthons in Crystal Engineering-A New Organic Synthesis. Angew. Chem Int. Ed. Engl. 1995, 34, 2311-2327. [CrossRef]

39. Etter, M. Encoding and Decoding Hydrogen-Bond Patterns of Organic Compounds. Acc. Chem. Res. 1990, 23, 120-126. [CrossRef]

40. Aiello, D.; Folliet, N.; Laurent, G.; Testa, F.; Gervais, C.; Babonneau, F.; Azaïs, T. Solid state NMR Characterization of Phenylphosphonic Acid Encapsulated in SBA-15 and Aminopropyl-modified SBA-15. Micropor. Mesopor. Mat. 2013, 166, 109-116. [CrossRef]

41. Kreuer, K.; Paddison, S.; Spohr, E.; Schuster, M. Transport in Proton Conductors for Fuel-Cell Applications: Simulations, Elementary Reactions, and Phenomenology. Chem. Rev. 2004, 104, 4637-4678. [CrossRef]

42. Ye, G.; Janzen, N.; Goward, G. Solid-State NMR Study of Two Classic Proton Conducting Polymers: Nafion and Sulfonated Poly(ether ether ketone)s. Macromolecules 2006, 39, 3283-3290. [CrossRef]

43. Thompson, E.; Capehart, T.; Fuller, T.; Jorne, J. Investigation of Low-Temperature Proton Transport in Nafion Using Direct Current Conductivity and Differential Scanning Calorimetry. Electrochem. Soc. 2006, 153, A2351-A2362. [CrossRef]

44. Zhao, R.; Rupper, P.; Gaan, S. Recent Development in Phosphonic Acid-Based Organic Coatings on Aluminum. Coatings 2017, 7, 133. [CrossRef]

45. Gawalt, E.S.; Avaltroni, M.J.; Koch, N.; Schwart, J. Self-Assembly and Bonding of Alkanephosphonic Acids on the Native Oxide Surface of Titanium. Langmuir 2001, 17, 5736-5738. [CrossRef]

46. Adden, N.; Gamble, L.J.; Castner, D.G.; Hoffmann, A.; Gross, G.; Menzel, H. Phosphonic Acid Monolayers for Binding of Bioactive Molecules to Titanium Surfaces. Langmuir 2006, 22, 8197-8204. [CrossRef] [PubMed]

47. Wan, X.; Lieberman, I.; Asyuda, A.; Resch, S.; Seim, H.; Kirsch, P.; Zharnikov, M. Thermal Stability of Phosphonic Acid Self-Assembled Monolayers on Alumina Substrates. J. Phys. Chem. C 2020, 124, 2531-2542. [CrossRef]

48. Cao, L.; Peng, Y.; Li, Z. Phosphonic Acid Self-assembled Monolayer Improved Properties of n-type Organic Field-effect Transistors in Air Ambient. RSC Adv. 2016, 6, 89794-89798. [CrossRef]

49. Bamba, T.; Ohtake, T.; Ohata, Y.; Nie, H.-Y.; Ban, T.; Yamamoto, S.-I. Octadecylphosphonic Acid Self-assembled Monolayers Obtained Using Rapid Dipping Treatments. Trans. Mat. Res. Soc. Jpn. 2018, 43, 305-309. [CrossRef]

50. Siegel, J.S.; Anet, F.A.I. Dichlorofluoromethane-d: A Versatile Solvent for VT-NMR Experiments. J. Org. Chem. 1988, 53, 2629-2630. [CrossRef]

51. Harris, R.K.; Becker, E.D.; Cabral de Menezes, S.M.; Goodfellow, R.; Granger, P. NMR Nomenclature. Nuclear Spin Properties and Conventions for Chemical Shifts (IUPAC Recommendations 2001). Pure Appl. Chem. 2001, 73, 1795-1818. [CrossRef]

52. Frisch, M.J.; Trucks, G.W.; Schlegel, H.B.; Scuseria, G.E.; Robb, M.A.; Cheeseman, J.R.; Scalmani, G.; Barone, V.; Petersson, G.A.; Nakatsuji, H.; et al. Gaussian, Inc.: Wallingford, CT, USA. 2016. Available online: http://gaussian.com/citation/ (accessed on 20 January 2021).

53. Arey, J.S.; Aeberhard, P.C.; Lin, I.-C.; Rothlisberger, U. Hydrogen Bonding Described Using Dispersion-Corrected Density Functional Theory. J. Phys. Chem. B 2009, 113, 4726-4732. [CrossRef] [PubMed]

54. Latypov, S.; Polyancev, F.; Yakhvarov, D.; Sinyashina, O. Quantum Chemical Calculations of ${ }^{31}$ P NMR Chemical Shifts: Scopes and Limitations. Phys. Chem. Chem. Phys. 2015, 17, 6976-6987. [CrossRef] [PubMed]

55. Dennington, R.; Keith, T.A.; Millam, J.M. GaussView, Version 5; Semichem Inc.: Shawnee Mission, KS, USA, 2009.

56. Chemcraft, Version 1.8. Available online: www.chemcraftprog.com (accessed on 20 January 2021).

57. Budzelaar, P.H.M. gNMR; Adept Scientific: Letchworth, UK, 2002.

58. Biegler-König, F.; Schönbohm, J.; Bayles, D. AIM2000-A Program to Analyze and Visualize Atoms in Molecules. J. Comp. Chem. 2001, 22, 545-559. 
59. Biegler-König, F.; Schönbohm, J. An Update to the AIM2000-Program for Atoms in Molecules. J. Comp. Chem. 2002, 23, 1489-1494. [CrossRef]

60. Shenderovich, I.G.; Burtsev, A.P.; Denisov, G.S.; Golubev, N.S.; Limbach, H.-H. Influence of the Temperature-dependent Dielectric Constant on the H/D Isotope Effects on the NMR Chemical Shifts and the Hydrogen Bond Geometry of the Collidine-HF Complex in $\mathrm{CDF}_{3} / \mathrm{CDClF}_{2}$ Solution. Magn. Reson. Chem. 2001, 39, 91-99. [CrossRef]

61. Dohnal, V.; Tkadlecova, M. A Simple Relation between 1H NMR Data and Mixing Enthalpy for Systems with Complex Formation by Hydrogen Bonding. J. Phys. Chem. B 2002, 106, 12307-12310. [CrossRef]

62. Ishikawa, R.; Kojima, C.; Ono, A.; Kainosho, M. Developing Model Systems for the NMR Study of Substituent Effects on the $\mathrm{N}-\mathrm{H} \cdots \mathrm{N}$ Hydrogen Bond in Duplex DNA. Magn. Reson. Chem. 2001, 39, 159-165. [CrossRef]

63. Limbach, H.-H.; Tolstoy, P.M.; Perez-Hernandez, N.; Guo, J.; Shenderovich, I.G.; Denisov, G.S. OHO Hydrogen Bond Geometries and NMR Chemical Shifts: From Equilibrium Structures to Geometric H/D Isotope Effects with Applications for Water, Protonated Water and Compressed Ice. Israel J. Chem. 2009, 49, 199-216. [CrossRef]

64. Sorgenfrei, N.; Hioe, J.; Greindl, J.; Rothermel, K.; Morana, F.; Lokesh, N.; Gschwind, R.M. NMR Spectroscopic Characterization of cCharge Assisted Strong Hydrogen Bonds in Brønsted Acid Catalysis. J. Am. Chem. Soc. 2016, 138, 16345-16354. [CrossRef]

65. Silski-Devlin, A.M.; Petersen, J.P.; Liu, J.; Turner, G.A.; Poutsma, J.C.; Kandel, S.A. Hydrogen-bonded Tetramers of Carbamazepine. J. Phys. Chem. C 2020, 124, 5213-5219. [CrossRef]

66. Dilovic, I.; Matkovic-Calogovic, D.; Kos, M.I. N-Benzyloxy-1H-benzotriazole-1-Carboxamide: A Hydrogen-bonded Tetramer Based upon a Rare R(4)4(20) Structural motif. Acta Cryst. C 2008, 64, 434-436. [CrossRef] [PubMed]

67. Yang, Y.; Xue, M.; Marshall, L.J.; de Mendoza, J. Hydrogen-bonded Cyclic Tetramers Based on Ureidopyrimidinones Attached to a 3,6-carbazolyl Spacer. Org. Lett. 2011, 13, 3186-3189. [CrossRef] [PubMed]

68. Sagan, B.L.; Walmsley, J.A. Evidence for the Existence of Hydrogen-bonded Cyclic Tetramers in Aqueous Solutions of Tetramethylammonium Guanosine 5'-monophosphate. Biochem. Biophys. Res. Comm. 1985, 128, 980-986. [CrossRef]

69. Larsen, R.W.; Suhm, M.A. The Benefits of Alternation and Alkylation: Large Amplitude Hydrogen Bond Librational Modes of Alcohol Trimers and Tetramers. Phys. Chem. Chem. Phys. 2010, 12, 8152-8157. [CrossRef] [PubMed]

70. Mella, M.; Harris, K.D.M. Pathways for Hydrogen Bond Switching in a Tetrameric Methanol Cluster. Phys. Chem. Chem. Phys. 2009, 11, 11340-11346. [CrossRef]

71. Denisov, G.S.; Tokhadze, K.G. Ultrastrong Hydrogen Bond in Gas Phase. Dimer of Dimethylphosphinic Acid. Dokl. Phys. Chem. 1994, 337, 117-119.

72. Espinosa, E.; Molins, E.; Lecomte, C. Hydrogen Bond Strengths Revealed by Topological Analyses of Experimentally Observed Electron Densities. Chem. Phys. Lett. 1998, 285, 170-173. [CrossRef]

73. Mata, I.; Alkorta, I.; Espinosa, E.; Molins, E. Relationships between Interaction Energy, Intermolecular Distance and Electron Density Properties in Hydrogen Bonded Complexes under External Electric Fields. Chem. Phys. Lett. 2011, 507, 185-189. [CrossRef]

74. Kumar, G.A.; McAllister, M.A. Theoretical Investigation of the Relationship between Proton NMR Chemical Shift and Hydrogen Bond Strength. J. Org. Chem. 1998, 63, 6968-6972. [CrossRef]

75. Tupikina, E.Y.; Sigalov, M.; Shenderovich, I.G.; Mulloyarova, V.V.; Denisov, G.S.; Tolstoy, P.M. Correlations of NHN hydrogen bond energy with geometry and ${ }^{1} \mathrm{H}$ NMR chemical shift difference of $\mathrm{NH}$ protons for aniline complexes. J. Chem. Phys. 2019, 150, 114305. [CrossRef] [PubMed]

76. Denisov, G.S.; Bureiko, S.F.; Kucherov, S.Y.; Tolstoy, P.M. Correlation Relationships between the Energy and Spectroscopic Parameters of Complexes with F...HF Hydrogen Bond. Doklady Phys. Chem. 2017, 475, 115-118. [CrossRef] 